\title{
NINETEEN YEARS STUDY OF BETA-THALASSAEMIA IN SLOVAKIA
}

\author{
Viera Fábryová1, Pavol Babušík², Zuzana Laluhová-Striežencová3, Monika Drakulová4, Martina Oslancová3, \\ Martina Macichová ${ }^{5}$, Adriana Sakalová ${ }^{6}$ \\ ${ }^{1}$ Department of Haematology, Military Hospital, Bratislava, Slovakia \\ ${ }^{2}$ Laboratory of Molecular Genetics, ProGen Company, Nitra, Slovakia \\ ${ }^{3}$ Department of Haematology, Pediatric Faculty Hospital and Clinic, Bratislava, Slovakia \\ ${ }^{4}$ Laboratory of Haematology, Synlab Company, University Hospital in Kramáre, Bratislava, Slovakia \\ ${ }^{5}$ Department of Haematology, L. Pasteur Faculty Hospital, Košice, Slovakia \\ ${ }^{6}$ Department of Haematology and Transfusiology, Slovak Postgradual University, Bratislava, Slovakia
}

\section{SUMMARY}

Background: Beta-thalassaemia is a congenital disorder caused by point mutations in a haemoglobin beta-globin chain. The heterozygous form produces microcytosis and normal iron levels, however, haemoglobin electrophoresis shows elevated amounts of haemoglobin $A_{2}$ and eventually foetal haemoglobin $\mathrm{F}$ as well.

Methods: Between 2005-2011, in three centres in Slovakia, carriers of beta-thalassaemic genes or other haemoglobinopathies were searched for. Diagnosis was performed by haematologists whereby the family history was evaluated, together with the overall clinical condition, blood count and blood smear, iron parameters, haemolysis and haemoglobin electrophoresis testing. A proportion of patients was examined by molecular genetic methods.

Results: A clinical suspicion of the heterozygous form of beta-thalassaemia was documented in 402 patients $(21.9 \%)$ out of a total of 1,834 examinations. From these patients, 87 underwent molecular genetic testing and mutations of beta globin genes were identified in 70 of them, where the most frequent mutations were IVS 2.1 (28.5\%), IVS 1.110 (25.6\%) and IVS 1.1 (11.3\%). Evidence of haemoglobin S (sickle cell anaemia) was also notable in one case (patient of African origin). Unusually high levels of haemoglobin $\mathrm{F}$ (6-21\%) were found in 23 adult subjects.

Conclusion: The study showed that there is a higher number of heterozygotes for beta-thalassaemia and rarely haemoglobinopathies. It is necessary to continue in search of pathological gene carriers in Slovakia.

Key words: beta-thalassaemia, beta-globin chain, gene mutation, epidemiological study

Address for correspondence: V. Fábryová, St. Michael Hospital, Cesta na Červený most 1, Bratislava, Slovakia. E-mail: viera.fabryova@nsmas.sk

\section{INTRODUCTION}

Little attention is paid to the congenital disorders of red blood cells and other emergent haematological problems due to their rare occurrence and the fact that they do not cause significant trouble to the carrier. Nonetheless, haematologists encounter a small incidence of anaemia, which remain outstanding and present an unnecessary burden on the patient's diagnostic and therapeutic interventions. Haemoglobinopathies prevail, betathalassaemia in particular.

Although the disease can be most commonly found in the Mediterranean region and in South-East Asia due to migration, we can come across it anywhere in the world. Given the raids from South-East Asia in the past centuries and migration, Slovakia is no exception. Similarly, since opening the borders in the past decades, we can encounter the aforementioned mutations in foreign nationals visiting Slovakia and our medical personnel working abroad encounter these mutations abroad. At the same time, they occur in the offsprings of mixed marriages where a spouse comes from the most seriously affected area.
Beta-thalassaemia results from mutations in the beta-globin molecule. In the clinical presentation, it varies from quite subtle changes to severe anaemia. Commonly, the heterozygotes present a noticeable microcytosis of erythrocytes, normal values of iron parametres, and elevated haemoglobin electrophoresis fractions $\mathrm{A}_{2}\left(\mathrm{HbA}_{2}\right)$, possibly also haemoglobin $\mathrm{F}(\mathrm{HbF})$.

In the past, diagnosis of beta-thalassaemia was established rather sporadically, therefore, in 1993, we decided to conduct an epidemiological study with the aim to actively seek out carriers of beta-thalassaemic genes in Slovakia.

The study was aimed at:

- simplifying diagnosis of beta-thalassaemia and avoiding unnecessary treatment by iron preparations;

- determining the prevalence and type of mutations found in our territory;

- according to the type of prevailing mutations, selecting the appropriate genetical methods for their screening;

- introducing genetic counselling (particularly before entering into a marriage with a partner from the affected area); - entering the results into the EU-wide screening programme for haemoglobinopathies. 
The first part of the study lasted 12 years (1993-2004) with 70 doctors participating in the study. The centre of the study were 3 haematology centres in Bratislava. Diagnosis was based on a clinical examination with thorough family history, particularly with the finding of microcytosis of erythrocytes in the blood test, normal values of iron parametres, and elevated levels of $\mathrm{HbA}_{2}$, possibly also $\mathrm{HbF}$ in the electrophoresis of haemoglobin.

Overall, we managed to record 346 patients with suspected heterozygous beta-thalassaemia, namely heterozygotes with beta-thalassaemia minor or intermedia from the clinical view. In addition, we conducted molecular genetic testing in 37 patients ( $10.7 \%$ of the studied group). The prevailing mutation was IVS 1.110 and IVS 2.1, which are common Mediterranean mutations. It reflects the historical gene transfer onto our territory from the Mediterranean area. Results of the study were published $(1,2)$.

After evaluation of the first part of the study, it was clear that the recorded cases represented only a fraction of potentially affected population. Since we kept receiving requests for diagnostics of haemoglobinopathies from other centres, the need for diagnosing haemoglobinopathies, centralisation of patients as well as genetic counselling became obvious. We decided to establish a Study Group for Beta-thalassaemia and Other Haemoglobinopathies in 2005 and continued in the haemoglobinopathy search in Slovakia. Molecular genetic diagnosing of beta-thalassaemia conducted in Slovakia significantly contributes to this field. In this paper, we present outcomes of the second phase of the study which lasted 7 years (2005-2011).

\section{MATERIALS AND METHODS}

Patients with suspected beta-thalassaemia were addressed in the local haematological surgeries or were sent directly to the aforementioned haematological centres.

Criteria for participating in the study:

- history (family history);

- objective testing (e.g. splenomegaly);

- microcytosis of erythrocytes in the blood count: MCV (medium volume of erythrocytes) below $78 \mathrm{fl}$, possibly $\mathrm{MCH}$ (medium size of haemoglobin in the erythrocyte) below $25 \mathrm{pg}$, anaemia was not necessarily present;

- finding in the peripheral blood smear: microcytes, target erythrocytes, possibly further morphological changes;

- normal or elevated levels of serum iron, particularly ferritine or persistent microcytosis of erythrocytes following treatment by iron preparations;

- positive test for haemolysis (increased reticulocyte count, reduced levels of haptoglobin, elevated indirect bilirubin, etc.).

Methods:

- parameters of blood counts (reticulocyte count, MCV, MCH) were obtained from normal high-parametre counters of blood cells;

- peripheral blood smears were evaluated microscopically (Pappenheim's staining);

- examination of parametres of iron, bilirubin or other biochemical parametres was conducted through standard biochemical analysers; haptoglobin test was performed by laser nephelometry;

- electrophoresis of haemoglobin tests were carried out by the acetate celulose sheets method in the aforementioned haema- tological centres. The values of $\mathrm{HbA}_{2}$ fraction below 3.5\% and $\mathrm{HbF}$ below $1.1 \%$ (adults) were considered normal. Only patients meeting the above mentioned criteria were able to participate in the study.

If the results came back positive, we would ask the proband's relatives to be referred to us; this included ascending, descending and horizontal line of the family.

At the same time, we commenced cooperation with the ProGen Laboratory (Molecular genetics laboratory) in Nitra, which performed diagnostics of beta-thalassaemia and other genetic haematological disfunctions. In rare cases, we consulted with the Department of Biology, Faculty of Medicine, Palacký University Olomouc.

\section{RESULTS}

Results can be found in the following Tables:

Table 1: Results of examinations conducted by the haematological laboratory of the Synlab Company, University Hospital, Kramáre, Bratislava.

Table 2: Results of examinations conducted by the haematological laboratory of the Paediatric Faculty Hospital and Clinic, Bratislava.

Table 3: Results of examinations conducted by the haematological laboratory of the L. Pasteur Faculty Hospital, Košice.

The first and the second column of the Tables show the number of examinations of haemoglobin electrophoresis in each year as well as the total number of examinations in six years. The third column shows the number of positive results of tests, i.e. $\mathrm{HbA}_{2}$ above $3.5 \%$. The fourth column states the number of positive results where, apart from the elevated levels of haemoglobin $\mathrm{A}_{2}$, haemoglobin $F$ was above 1.1 percent. In evaluating the outcome of haemoglobin, we excluded children under one year of age. Overall, we recorded 23 foreign nationals of Asian origin and their children.

In Table 1 (the Synlab Company), we find that the total number of positive results (increase in $\mathrm{HbA}_{2}$ above 3.5\%) accounted for 189 cases $(52.3 \%)$ out of the total number of tests. The portion of positive results recorded by the Paediatric Faculty Hospital and Clinic in Bratislava represented 158 cases (16.2\%) in Table 2 and the Faculty Hospital in Košice recorded 55 cases (9.16\%) in Table 3. In the last laboratory, haemoglobin S (sickle cell anaemia) was discovered in a family of a foreign national. Out of a total of 1,834 electrophoresis of haemoglobin examinations in three

Table 1. Number of examined patients, results with higher level of $\mathrm{HbA}_{2}$ and results with higher $\mathrm{HbA}_{2}+\mathrm{HbF}$. University Hospital Kramáre, Bratislava, Synlab Comp., haematology laboratory

\begin{tabular}{|l|c|c|c|}
\hline Year & $\begin{array}{c}\text { Number of } \\
\text { patients }\end{array}$ & $\begin{array}{c}\text { Number of } \\
\mathrm{HbA}_{2}>3.5 \%\end{array}$ & $\begin{array}{c}\text { Number of } \\
\mathrm{HbF}>1.1 \%\end{array}$ \\
\hline 2005 & - & - & - \\
\hline 2006 & - & - & - \\
\hline 2007 & 45 & 24 & 24 \\
\hline 2008 & 78 & 49 & 49 \\
\hline 2009 & 144 & 85 & 83 \\
\hline 2010 & 94 & 31 & 22 \\
\hline Total & 361 & 189 & 178 \\
\hline
\end{tabular}


Table 2. Number of examined patients, results with higher level of $\mathrm{HbA}_{2}$ and results with higher $\mathrm{HbA}_{2}+\mathrm{HbF}$. Pediatric Faculty Hospital, Bratislava, Department of Haematology

\begin{tabular}{|l|c|c|c|}
\hline Year & $\begin{array}{c}\text { Number of } \\
\text { patients }\end{array}$ & $\begin{array}{c}\text { Number of } \\
\mathrm{HbA}_{2}>3.5 \%\end{array}$ & $\begin{array}{c}\text { Number of } \\
\mathrm{HbA_{2 }}>3.5 \%, \\
\mathrm{HbF}>1.1 \%\end{array}$ \\
\hline 2005 & 166 & 20 & 14 \\
\hline 2006 & 118 & 29 & 16 \\
\hline 2007 & 122 & 22 & 18 \\
\hline 2008 & 176 & 33 & 23 \\
\hline 2009 & 195 & 27 & 22 \\
\hline 2010 & 198 & 27 & 22 \\
\hline Total & 975 & 158 & 115 \\
\hline
\end{tabular}

Table 3. Number of examined patients, results with higher level of $\mathrm{HbA}_{2}$ and with higher level of $\mathrm{HbA}_{2}+\mathrm{HbF}$. L. Pasteur Faculty Hospital, Košice, Department of haematology

\begin{tabular}{|l|c|c|c|}
\hline Year & $\begin{array}{c}\text { Number of } \\
\text { patients }\end{array}$ & $\begin{array}{c}\text { Number of } \\
\mathrm{HbA}_{2}>3.5 \%\end{array}$ & $\begin{array}{c}\text { Number of } \\
\mathrm{HbA}_{2}>3.5 \%, \\
\mathrm{HbF}>1.1 \%\end{array}$ \\
\hline 2005 & 45 & $\mathbf{5}$ & 4 \\
\hline 2006 & 92 & $\mathbf{8}$ & 6 \\
\hline 2007 & 81 & 4 & 0 \\
\hline 2008 & 95 & 4 & 1 \\
\hline 2009 & 71 & $\mathbf{9}$ & 2 \\
\hline 2010 & 114 & $\mathbf{2 5}$ & 7 \\
\hline Total & 498 & $\mathbf{5 5}$ & 30 \\
\hline
\end{tabular}

aforementioned centres the number of suspected heterozygous betathalassaemia cases was 402 (21.9\%). It is noteworthy that in 23 cases, representing 5 families, an unusually high level of $\mathrm{F}$ haemoglobin was detected in adults (6-21\%) without elevated levels of $\mathrm{HbA}_{2}$; we contemplated an unknown form of haemoglobinopathy or hereditary persistence of haemoglobin F. We carried out molecular-genetic testing for beta-thalassaemia in 87 patients and found mutations of beta-globin chain in 70 of them. Table 4 illustrates analysis results. The most frequent mutations included IVS $2.1(\mathrm{G} \rightarrow \mathrm{A})$ in $28.5 \%$, IVS $1.110(\mathrm{G} \rightarrow \mathrm{A})$ in $25.6 \%$ and IVS $1.1(\mathrm{G} \rightarrow \mathrm{A}) 11.3 \%$, which represent typical Mediterranean mutations spread on our territory by immigrants from this area. Particular mutation $-\mathrm{cd} 17$ (AAG $\rightarrow$ TAG) (Lys STOP) has been demonstrated in the Department of Biology in Olomouc. In the remaining cases, beta-thalassaemia was either not detected or it was a case of mutations which were impossible to detect by the genetic testing available. Table 5 ilustrates all Mediterranean mutations examined in this study.

\section{DISCUSSION}

Every year, 300,000 children are born with serious congenital hemoglobinopathies in the world; approximately two thirds of them in less or average developed countries. Eighty-three \% of them suffers from sickle cell anaemia, $17 \%$ from thalassaemia.
Table 4. Mutations of beta globin genes in the studied group. Relative proportion of patients with molecular genetic testing and identified mutations (\%)

\begin{tabular}{|c|c|c|}
\hline Mutations & $\begin{array}{l}\text { Number of patients } \\
\text { (absolute) }\end{array}$ & $\begin{array}{c}\text { Relative proportion } \\
\text { of patients }(\%)\end{array}$ \\
\hline IVS $2.1(G \rightarrow A)$ & 20 & 28.5 \\
\hline IVS $1.110(G \rightarrow A)$ & 18 & 25.6 \\
\hline IVS $1.1(G \rightarrow A)$ & 8 & 11.3 \\
\hline IVS $1.6(T \rightarrow C)$ & 7 & 10.0 \\
\hline $\mathrm{Cd} 39(\mathrm{C} \rightarrow \mathrm{T})$ & 5 & 7.1 \\
\hline IVS $2.745(C \rightarrow G)$ & 4 & 5.7 \\
\hline $\operatorname{cd} 27(\mathrm{G} \rightarrow \mathrm{T})$ Knossos & 3 & 4.3 \\
\hline $\operatorname{cd} 5(-\mathrm{CT})$ & 2 & 2.7 \\
\hline $\operatorname{cd} 8(-A A)$ & 2 & 2.7 \\
\hline $\begin{array}{l}\text { cd } 17(\mathrm{AAG} \rightarrow \mathrm{TAG}) \\
\text { Lys STOP }\end{array}$ & 1 & 2.1 \\
\hline Total & 70 & 100 \\
\hline
\end{tabular}

A - adenine, cd - codon, C - cytosine, G - guanine, $T$ - thymine

Table 5. Mediterranean mutations of beta globin genes examined in Slovakia. Marked mutations were found in our studied group

\begin{tabular}{|c|c|c|c|c|c|}
\hline Position & Mutation & $\beta$ thalas. & Position & Mutation & $\beta$ thalas. \\
\hline-101 & $\mathrm{C} \rightarrow \mathrm{T}$ & $\beta^{+}$ & $\operatorname{cd} 39$ & $C \rightarrow T$ & $\beta^{0}$ \\
\hline-87 & $C \rightarrow G$ & $\beta^{+}$ & IVS 1.1 & $\mathbf{G} \rightarrow \mathbf{A}$ & $\beta^{0}$ \\
\hline-30 & $\mathrm{~T} \rightarrow \mathrm{A}$ & $\beta^{+}$ & IVS 1.5 & $G \rightarrow C$ & $\beta^{+}$ \\
\hline $\mathrm{cd} 5$ & -CT & $\beta^{0}$ & IVS 1.6 & $T \rightarrow C$ & $\beta^{+}$ \\
\hline $\mathrm{cd} 6$ & $\mathrm{G} \rightarrow \mathrm{A}, \mathrm{HbC}$ & - & IVS 1.110 & $\mathbf{G} \rightarrow \mathbf{A}$ & $\beta^{+}$ \\
\hline $\mathrm{cd} 6$ & $\mathrm{~A} \rightarrow \mathrm{T}, \mathrm{HbS}$ & - & IVS 1.116 & $T \rightarrow G$ & $\beta^{0}$ \\
\hline $\mathrm{cd} 6$ & $-A$ & $\beta^{0}$ & IVS 1.130 & $\mathrm{G} \rightarrow \mathrm{C}$ & $\beta^{0}$ \\
\hline $\mathrm{cd} 8$ & $-\mathrm{AA}$ & $\beta^{0}$ & $\operatorname{cd} 44$ & $-C$ & $\beta^{0}$ \\
\hline $\operatorname{cd} 8 / 9$ & $+G$ & $\beta^{0}$ & IVS 2.1 & $\mathbf{G} \rightarrow \mathbf{A}$ & $\beta^{0}$ \\
\hline cd 15 & $\mathrm{TGG} \rightarrow \mathrm{TGA}$ & $\beta^{0}$ & IVS 2.745 & $C \rightarrow G$ & $\beta^{+}$ \\
\hline cd 27 & $\begin{array}{l}\mathrm{G} \rightarrow \mathrm{T}, \mathrm{Hb} \\
\mathrm{Knossos}\end{array}$ & $\beta^{+}$ & IVS 2.848 & $\mathrm{C} \rightarrow \mathrm{A}$ & $\beta^{+}$ \\
\hline
\end{tabular}

A - adenine, cd - codon, $\mathrm{C}$ - cytosine, $\mathrm{G}$ - guanine, $\mathrm{T}$ - thymine

Haemoglobinopathies account for $3.4 \%$ of children mortality under 5 years of age in the world. Approximately $7 \%$ of pregnant women worldwide are carriers of beta or alpha-thalassaemia genes, haemoglobin S, C, D or E genes. With the continually improving hygiene stardands in third world countries, the percentage of neonatal and child mortality decreases, which results not only in an increase in surviving severe forms of haemoglobinopathies, but also in the number of mutated genes carriers.

In Sout-East Asian countries with high prevalence of haemoglobinopathies, there is a long-term effort to map the genetic region and introduce effective measures to reduce their occurrence. For example, in Japan, beta-thalassaemia is mapped very well, the incidence of beta-thalassaemic genes is 1 in 1000 inhabitants (3). In India, they discovered that $4.05 \%$ carriers of beta-thalassaemic genes (from 1 to $17 \%$ depending on the area) (4) can be found 
among the population. In Bahrain, in a 10-year study involving 60,000 healthy individuals, $3.5 \%$ carriers of the gene were found; from among 13 types of known mutations, 4 of them represented $80 \%(5)$. In the US, a study conducted in California between 1990-1996 revealed $0.17 \%$ incidence of sickle cell anaemia or thalassaemia in subjects of white non-Hispanic origin. In the Afro-American population, the incidence was significantly higher; haemoglobin $\mathrm{S}$ was found in $4 \%$, in $1.5 \%$ haemoglobin $\mathrm{C}$ and in $4 \%$ beta-thalassaemia.

A large number of studies from the 80 s and 90 s was mapping the situation in the most affected areas of the Middle East and Southern Europe (6-8). In central Europe, in countries with a large number of immigrants, e.g. in Germany, 300 patients with beta-thalassaemia major were recorded (9) in the year 2000 , and in Switzerland, 2,672 heterozygotes with beta-thalassaemia were recorded in an epidemiological study conducted between 1968-1974. Only 2.6\% were native people, the remaining were immigrants from Turkey or Southern Europe. Overall, 56 homozygotes with a severe form of the disease were recorded (10). Since the establishment of the European Union, post-communist countries (Romania, Bulgaria, former Yugoslavia) have started to pay attention to this issue. For example, in a study in Romania, the incidence of the beta-thalassaemic gene was found in $0.49 \%$ (11). Great Britain has become exemplary in diagnosing and treating haemoglobinopathies. As a multi-cultural country, it had to start tackling the high prevalence of haemoglobinopathies in some minority groups of the population several decades ago. In 1999, all types of recorded haemoglobinopathies were evaluated in the Thalassaemia Register and in the Register for Prenatal Diagnosis for Haemoglobin Disorders $(12,13)$.

Due to the large influx of immigrants to the whole of Europe in the last decade, the problem of haemoglobinopathies has become more prominent. A necessity to monitor their prevalence in immigrants as well as in the native population has emerged given the increasing number of mixed marriages. It is interesting to notice that in the recent years the prevalence of haemoglobinopathies has been higher in Western European countries than in the "classic countries" like Greece, Italy, Sardinia, etc. The structure of haemoglobinopathies has changed; the number of carriers of sickle cell anaemia increases which is caused particularly by the inflow of immigrants from Africa $(14,15)$. The situation induced the need to centralise and analyse the statistical data on the incidence of diseases for better diagnosis, treatment and prevention. For this purpose, WHO established a Centre for Clinical and Applied Bioinformatics and CHIME's WHO Collaborating Centre for the Community Control of Hereditary Disorders (Modells' almanach). It monitors the epidemiology of haemoglobinopathies, provides information, trains doctors and analyses the financial costs. The Centre monitors the situation virtually in the entire world and maintains a database which is regularly updated. WHO Bulletin of 2008 states that 39,303 children affected by beta-thalassaemia are born every year and that there are 25,866 transplants and a number of those dependent on blood transfusions and the chelating therapy. In Europe, 992 children suffering from a severe form of the disease are born every year (16).

In developed countries, diagnostics are performed in centres attached to hospitals or on an outpatient basis. The centres have their own protocols which are derived from the patient population, type of the medical centre, laboratory and the testing method.
Particular emphasis is placed on prenatal examination when both parents are carriers of severe mutations and are considering premature termination of pregnancy. Prenatal diagnosis can be avoided by conducting screening, e.g. in Cyprus and in Greece. In countries where marriages between relatives are common and the family is a carrier of the known form of haemoglobinopathy mutations, it is recommended to examine the whole family (Pakistan) (17). The rules of prevention (10) are constantly being improved and simpler screening methods are introduced, e.g. bloodshot screening (18).

In the year 1993, in the former Czechoslovak Republic, an extensive study to search the most common mutations of betathalassaemia was conducted (19). The study found 12 different mutations in the population. The most often were IVS $1.1(\mathrm{G} \rightarrow \mathrm{A})$ $46.3 \%, \mathrm{CD} 39(\mathrm{C} \rightarrow \mathrm{T}) 11.1 \%$ and IVS $2.1(\mathrm{G} \rightarrow \mathrm{A})$ 9.3\%. The results of our study were very similar. We acknowledged the occurence of 10 mutations, which were also of the Mediterranean origin. The most common were IVS $2.1(\mathrm{G} \rightarrow \mathrm{A}) 28.5 \%$, IVS 1.110 $(\mathrm{G} \rightarrow \mathrm{A})$ 25.6\% and IVS $1.1(\mathrm{G} \rightarrow \mathrm{A}) \mathbf{1 1 . 3 \%}$.

Our patients are only heterozygotes with beta-thalassaemia minima, minor or intermediate in good clinical conditions. They do not require any transfusion or chelating therapy. However, in the past, beta-thalassaemia major occured in Slovakian descendants of Croatian immigrants.

Although Slovakia has been spared of the aforementioned problems so far, we cannot assume that they will not appear in Slovakia in the future. Due to globalisation, migration of the population and hereditary beta-thalassaemic genes in our population, the incidence of homozygotous forms could be a surprise to us.

We have made the first step in this area. It is comforting that haemoglobinopathies have started to be considered in the diagnostics and patients are not treated by iron preparations unnecessarily. The awareness has increased also among the population, the patients actively seek professional medical advice. The possibilities of genetic testing are expanding, the affected families are sought out and offered counselling.

Haemoglobinopathies are a global issue and the situation can be addressed only through concentrated efforts of national haemotological societies with the contribution of major international health organisations and support funds (19-21).

\section{Acknowledgements}

We would like to thank Prof. MUDr. Karel Indrák, DrSc., Doc. RNDr. Vladimír Divoký, PhD and RNDr. Martina Divoká (Palacký University Olomouc) for valuable advice and assistance and all our colleagues who have participated in the work of the study group for haemoglobinopathies in Slovakia. The study group operates without any financial support or personnel.

\section{REFERENCES}

1. Fábryová V, Sakalová A. Latest news in the diagnostics, treatment and prevention of beta-thalassemia. Lek Obz. 2006 Oct;55(10):430-2. (In Slovak.)

2. Fábryová V. Beta-talasémie. Bratislava: Herba; 2007. (In Slovak.)

3. Harano T. Hemoglobinopathy. Kobe (Japan): Sysmex Corp; 2004.

4. Madan N, Sharma S, Sood SK, Colah R, Bhatia LH. Frequency of $\beta$-thalassemia trait and other hemoglobinopathies in northern and western India. Indian J Hum Genet. 2010 Jan;16(1):16-25. 
5. Al-Arrayed SS. Beta thalassemia frequency in Bahrain: a ten year study. Bahrain Med Bull. 2010;32(2):1-5.

6. Ginsberg G, Tulchinsky T, Filon D, Goldfarb A, Abramov L, Rachmilevitz EA. Cost-benefit analysis of a national thalassaemia prevention programme in Israel. J Med Screen. 1998;5(3):120-6.

7. Cao A, Rosatelli MC, Galanello R. Control of beta-thalassaemia by carrier screening, genetic counselling and prenatal diagnosis: the Sardinian experience. Ciba Found Symp. 1996;197:137-51.

8. Galanello R, Eleftheriou A, Traeger-Synodinos J, Old J, Petrou M, Angastiniotis M, editors. Prevention of thalassaemias and other haemoglobin disorders. Nicosia: Thalassaemia International Federation; 2003.

9. Cario H, Stahnke K, Sander S, Kohne E. Epidemiological situation and treatment of patients with thalassemia major in Germany: result of the German multicenter beta-thalassemia study. Ann Hematol. 2000 Jan;79(1):7-12.

10. Dankwa E, Killer D, Fischer S, Marti HR. Incidence of thalassemia in Switzerland. Schweiz Med Wochenschr. 1975 Jan 25;105(4):102-5. (In German.)

11. Frecus CE. Beta-thalassemia trait - epidemiological and clinical aspects in children in Constanta County [Ph.D. thesis]. University of Medicine and Pharmacy Craiova Faculty of General Medicine; 2010.

12. Modell B, Khan M, Darlison M. Survival in beta-thalassaemia major in the UK: data from the UK Thalassaemia Register. Lancet. 2000 Jun 10;355(9220):2051-2.

13. Wonke B, Modell M, Marlow T, Khan M, Modell B. Microcytosis, iron deficiency and thalassaemia in a multi-ethnic community: a pilot study. Scand J Clin Lab Invest. 2007;67(1):87-96.

14. Modell B, Darlison M, Birgens H, Cario H, Faustino P, Giordano PC, et al. Epidemiology of haemoglobin disorders in Europe: an overview. Scand J Clin Lab Invest. 2007;67(1):39-70.
15. Mañú Pereira M, Vives Corrons JL. Neonatal haemoglobinopathy screening in Spain. J Clin Pathol. 2009 Jan;62(1):22-5.

16. Modell B, Darlison M. Global epidemiology of haemoglobin disorders and derived service indicators. Bull World Health Organ. 2008 Jun;86(6):480-

17. Bain BJ. Haemoglobinopathy diagnosis. Oxford: Blackwell Publishing; 2006.

18. Streetly A, Latinovic R, Hall K, Henthorn J. Implementation of universal newborn bloodspot screening for sickle cell disease and other clinically significant haemoglobinopathies in England: screening results for 2005-7. J Clin Pathol. 2009 Jan;62(1):26-30.

19. Indrák K, Divoký V, Brabec V, Chrobák L, Mociková K, Sakalová A, et al. Dominant beta-thalassaemie alleles in the Czech and Slovak population (beta-thalassaemie mutations in the codons 112 (TA) and 121 (GT) amd unstable hemoglobin varriants Hradec Králové or alpha, 2, beta, 2, 115 (G17 Ala-Asp). Vnitr Lek. 1994;40(4):223-30.

20. Lenna-Russo D. Research profile on biomed experts, 2007 [Internet]. Elsevier; 2011 [cited 2012 Jun 11]. Available from: http://www.biomedexperts.com/.

21. Weatherall DJ. The inherited diseases of hemoglobin are an emerging global health burden. Blood. 2010 Jun 3;115(22):4331-6.

22. Weatherall DJ. Thalassaemia: the biography. Oxford: Oxford University Press; 2010.

Received December 16, 2011

Accepted in revised form July 2, 2012 